\title{
A Case of Fatal Rhino-Orbital Mucormycosis Associated With New Onset Diabetic Ketoacidosis and COVID-19
}

\author{
Salomon Waizel-Haiat ${ }^{1}$, Jose Alberto Guerrero-Paz ${ }^{1}$, Luis Sanchez-Hurtado ${ }^{2}$, Salvador Calleja-Alarcon ${ }^{2}$, \\ Laura Romero-Gutierrez ${ }^{2}$ \\ 1. Otolaryngology, Hospital de Especialidades “Dr. Bernardo Sepúlveda Gutiérrez” Centro Médico Nacional Siglo XXI, \\ Mexico City, MEX 2. Critical Care Medicine, Hospital de Especialidades “Dr. Bernardo Sepúlveda Gutiérrez” Centro \\ Médico Nacional Siglo XXI, Mexico City, MEX
}

Corresponding author: Salomon Waizel-Haiat, swaizel@hotmail.com

\section{Abstract}

Mucormycosis is an invasive fungal infection, often acute and extremely severe, occurring in patients with an underlying condition. Coinfection in patients with coronavirus disease 2019 (COVID-19) has been reported, often bacterial. A 24-year-old female is presented with acute fatal rhino-orbital mucormycosis and COVID-19.

We report one of the first cases of rhino-orbital mucormycosis and COVID-19. With this case, we highlight the importance of considering mycotic coinfection in COVID-19 patients with diabetes.

Categories: Ophthalmology, Otolaryngology, Infectious Disease

Keywords: rhinosinusitis, covid-19, mucormycosis, diabetic ketoacidosis (dka), fungal rhino sinusitis

\section{Introduction}

Mucormycosis (Zygomycosis) is an invasive fungal infection, often acute and extremely severe caused by opportunist and ubiquitous fungi belonging to the class Phygomycetes, subclass Zygomycetes, order Mucorales, family Mucoraceae; usually by the following species: Absidia corymbifera, Apophysomyces elegans, Cunninghamella bertholletiae, Mucor rouxii, Rhizomucor pussillus, Rhizopus arrhizus, and by species of the genus Saksenaea spp. The species mentioned above suppose the third cause of invasive fungal infection after Aspergillus and Candida spp in humans [1].

Review began 01/28/2021 Review ended 01/31/2021 Published 02/05/2021

\section{(c) Copyright 2021}

Waizel-Haiat et al. This is an open access article distributed under the terms of the Creative Commons Attribution License CC-BY 4.0., which permits unrestricted use, distribution, and reproduction in any medium, provided the original author and source are credited.
It is acquired by the establishment or implantation of the fungal spores in the oral, nasal and conjunctival mucosa (rhino-orbito-cerebral), by inhalation (pulmonary), or by the ingestion of contaminated food (digestive); as they quickly colonize nutriments rich in simple carbohydrates being glucose its main energy source [2].

Coinfection in patients with coronavirus disease 2019 (COVID-19) has been reported on multiple series, being bacterial in origin the most frequent; and fungal infection being reported only in severe cases [3-5].

Here we present a case of rhino-orbital mucormycosis associated with ketoacidosis secondary to recentonset diabetes mellitus and infection with severe acquired respiratory syndrome coronavirus 2 (SARS COV2).

\section{Case Presentation}

A 24-year-old female, resident of Mexico City, with past medical history of obesity and being exposed to family members with COVID-19, presented to the ED of our tertiary care center with respiratory failure and oxygen saturation of $80 \%$, given the findings she was managed in accordance with national and international guidelines.

Her family reported she began with pain in the left midface region six days prior, two days later she developed progressive left lid swelling and maxillary hypoesthesia; therefore, a primary care physician suspected infection, beginning treatment with oral antibiotics (amoxicillin-clavulanate 875/125 mg twicedaily) with partial remission of pain. However, on subsequent days she continued with progression of softtissue edema, being referred to our center for an extended study protocol and management.

Physical examination revealed severe left lid edema with extension to the upper lip and malar region, left proptosis with a hyperemic conjunctiva, and an opaque cornea which precluded further evaluation. Rhinoscopy revealed edema of the left nasal mucosa with an impaired response to vasoconstriction, without evidence of necrotic tissue or purulent discharge. Samples for a direct exam were taken. The oral cavity 


\section{Cureus}

examination only revealed pallor of hard palate mucosa. We could not assess sensitivity of facial structures due to the patient being sedated.

A contrast-enhanced CT of head and chest was performed revealing soft tissue swelling of the left inferior turbinate and thickening of the mucosa of the maxillary, ethmoid, and sphenoid sinuses on the ipsilateral side. Periorbital and midfacial structures of the left sides also had soft tissue swelling, with associated proptosis (Figure 1).

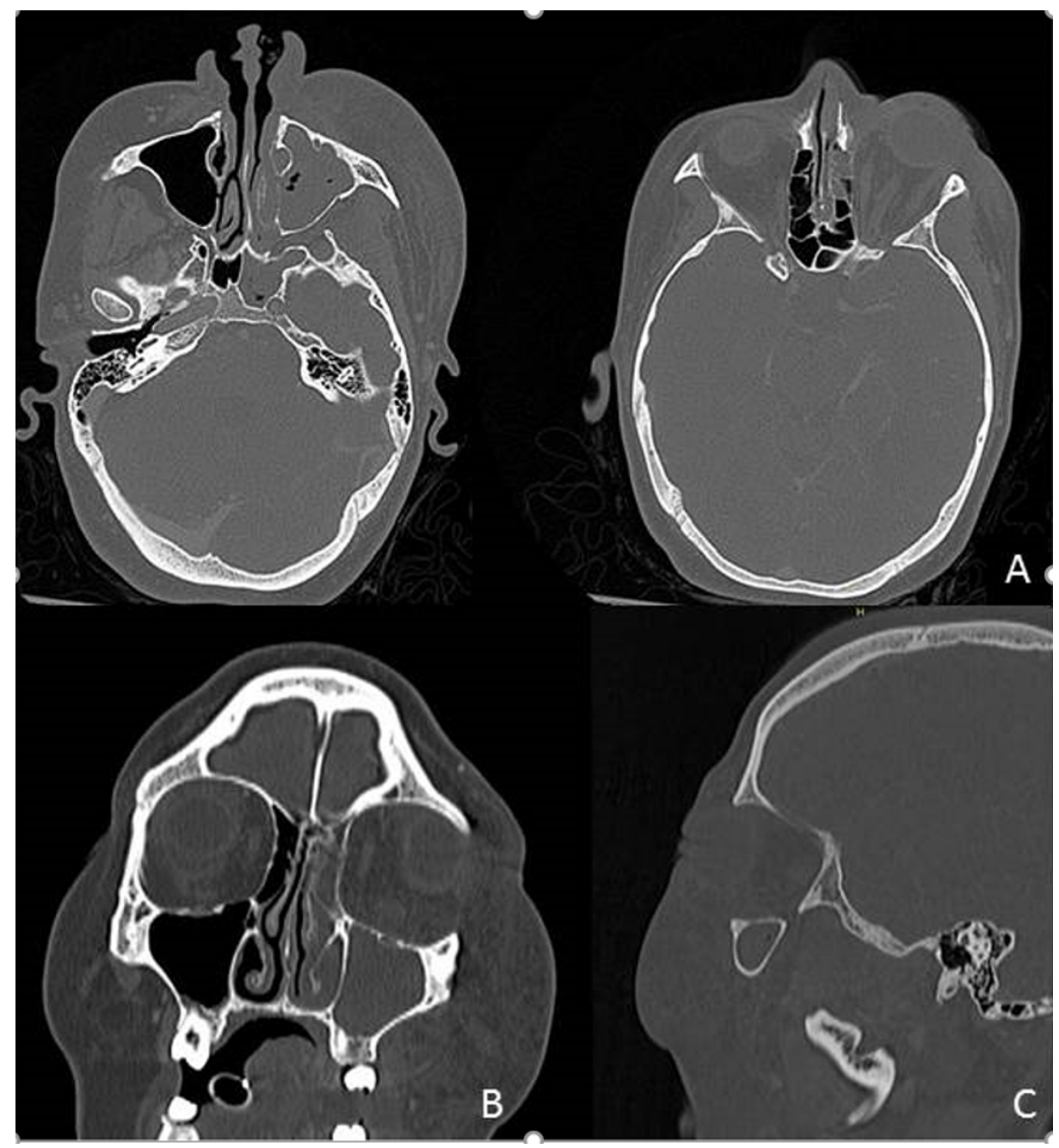

FIGURE 1: Contrast enhanced CT showing occupancy of the left maxillary, ethmoid, and sphenoid sinuses, without apparent intracranial involvement. Striation of the extraconal fat is observed in the lower left region, as well as periorbital and ipsilateral facial region with associated proptosis.

Axial (A), coronal (B) and sagittal (C).

The thorax section had findings suggestive of atypical pneumonia due to SARS COV-2, consisting of multiple parenchymatous zones with an increased density and bilateral distribution with peripheral predominance giving a ground-glass appearance, coexisting with consolidation of lower lobes (Figure 2). 


\section{Cureus}
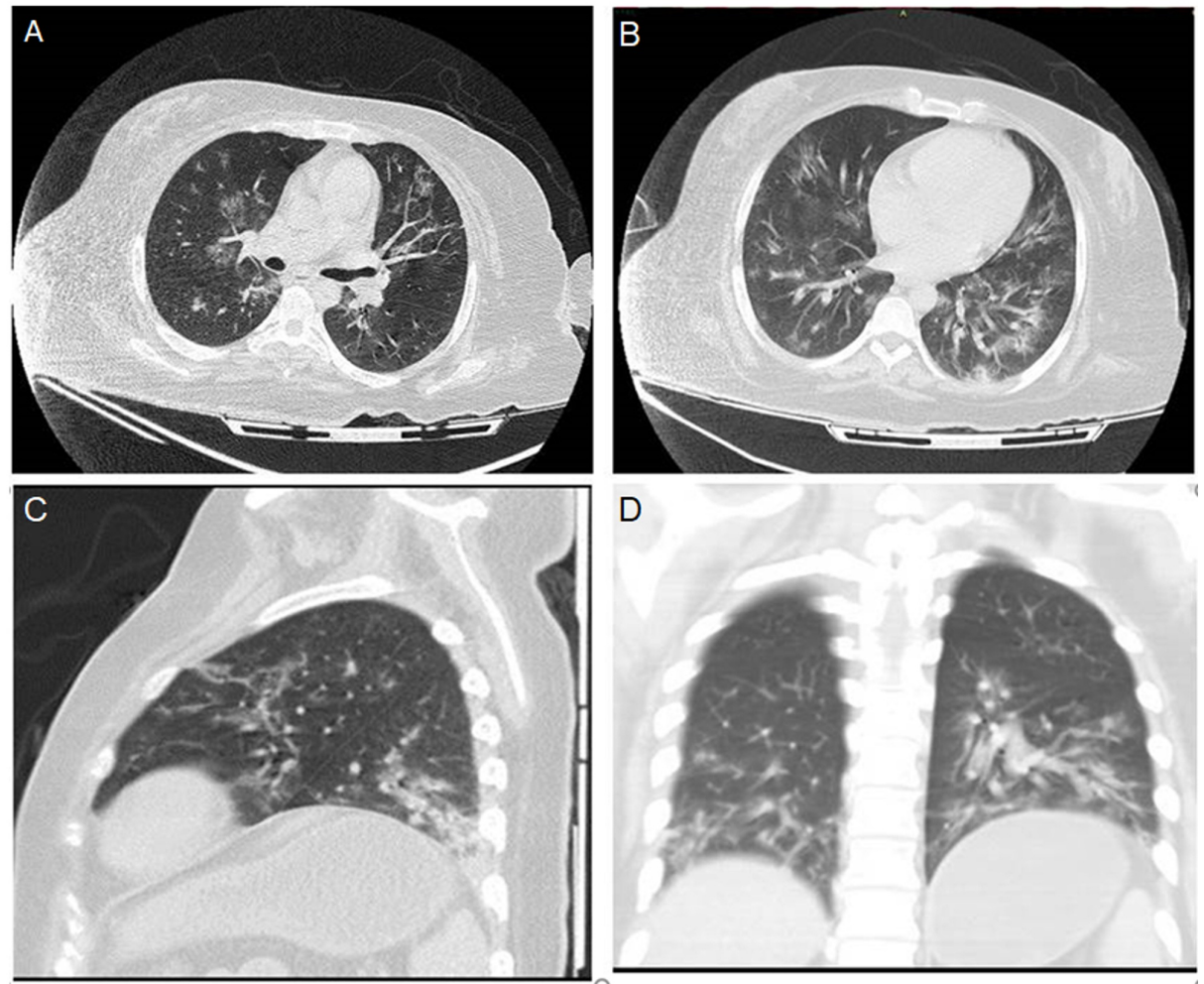

FIGURE 2: CT of the chest with multiple areas of increased density in a ground-glass pattern with diffuse bilateral distribution with peripheral predominance coexisting with consolidation in lower lobes and intralobular septal thickening.

Axial mainstem bronchii level (A), Axial right pulmonary artery level (B), Sagittal (C), Coronal (D)

We present the ancillary studies performed during her management at our center (Table 1). 


\section{Cureus}

\begin{tabular}{|c|c|c|c|}
\hline Parameter & Day 1 & Day 2 & Day 3 \\
\hline Glucose & 509 mg/dL & $\begin{array}{l}455 \\
\mathrm{mg} / \mathrm{dL}\end{array}$ & $331 \mathrm{mg} / \mathrm{dL}$ \\
\hline Urea & $25.7 \mathrm{mg} / \mathrm{dL}$ & $\begin{array}{l}42.8 \\
\mathrm{mg} / \mathrm{dL}\end{array}$ & $107.0 \mathrm{mg} / \mathrm{dL}$ \\
\hline Creatinine & $1.07 \mathrm{mg} / \mathrm{dL}$ & $\begin{array}{l}0.92 \\
\mathrm{mg} / \mathrm{dL}\end{array}$ & $2.95 \mathrm{mg} / \mathrm{dL}$ \\
\hline $\begin{array}{l}\text { Alanine } \\
\text { transaminase }\end{array}$ & $10 \mathrm{u} / \mathrm{L}$ & $14 \mathrm{u} / \mathrm{L}$ & $108 \mathrm{u} / \mathrm{L}$ \\
\hline $\begin{array}{l}\text { Aspartate } \\
\text { transaminase }\end{array}$ & $26 \mathrm{u} / \mathrm{L}$ & $34 \mathrm{u} / \mathrm{L}$ & $31 \mathrm{u} / \mathrm{L}$ \\
\hline $\begin{array}{l}\text { Lactic } \\
\text { dehydrogenase }\end{array}$ & $373 \mathrm{u} / \mathrm{L}$ & $289 \mathrm{u} / \mathrm{L}$ & $1395 \mathrm{u} / \mathrm{L}$ \\
\hline Albumin & $4.9 \mathrm{~g} / \mathrm{dL}$ & $2.9 \mathrm{~g} / \mathrm{dL}$ & - \\
\hline Potassium & $4.50 \mathrm{mEq} / \mathrm{L}$ & $\begin{array}{l}3.3 \\
\mathrm{mEq} / \mathrm{L}\end{array}$ & $7.80 \mathrm{mEq} / \mathrm{L}$ \\
\hline Sodium & 127 mEq/L & $\begin{array}{l}145 \\
\mathrm{mEq} / \mathrm{L}\end{array}$ & $151 \mathrm{mEq} / \mathrm{L}$ \\
\hline Leucocytes & $23 \times 10^{\wedge} 3 / \mu \mathrm{L}$ & $\begin{array}{l}23 \mathrm{X} \\
10^{\wedge} 3 / \mu \mathrm{L}\end{array}$ & $16 \times 10^{\wedge} 3 / \mu \mathrm{L}$ \\
\hline Neutrophils & $20.58 \times 10^{\wedge} 3 / \mu \mathrm{L}$ & $\begin{array}{l}21.68 \mathrm{x} \\
10^{\wedge} 3 / \mu \mathrm{L}\end{array}$ & $13.2 \times 10^{\wedge} 3 / \mu \mathrm{L}$ \\
\hline Platelets & $398 \times 10^{\wedge} 3 / \mu \mathrm{L}$ & $\begin{array}{l}302 \\
x 10^{\wedge} 3 / \mu \mathrm{L}\end{array}$ & $64 \times 10^{\wedge} 3 / \mu \mathrm{L}$ \\
\hline $\begin{array}{l}\text { Prothrombin } \\
\text { time }\end{array}$ & $18.4 \mathrm{~s}$ & $17.7 \mathrm{~s}$ & $26.4 \mathrm{~s}$ \\
\hline Fibrinogen & $1113.00 \mathrm{mg} / \mathrm{dL}$ & - & 1029 mg/dL \\
\hline D- Dimer & $3.12 \mu \mathrm{g} / \mathrm{mL}$ & - & $15.88 \mu \mathrm{g} / \mathrm{mL}$ \\
\hline Urinalysis & $\begin{array}{l}\text { pH 5, density } 1.025 \text {, proteins } 150 \mathrm{mg} / \mathrm{dL} \text {, glucose } \\
1000 \mathrm{mg} / \mathrm{dL} \text {, Ketones } 150 \mathrm{mg} / \mathrm{dL}\end{array}$ & - & - \\
\hline $\begin{array}{l}\text { Arterial } \\
\text { gasometry }\end{array}$ & pH 6.9, pCO2 23.3, HCO3 4.7, Anion gap 20.3 & - & - \\
\hline Procalcitonin & - & $\begin{array}{l}23.66 \\
\mathrm{ng} / \mathrm{mL}\end{array}$ & - \\
\hline $\begin{array}{l}\text { Central } \\
\text { hemoculture }\end{array}$ & No growth & & \\
\hline $\begin{array}{l}\text { SARS COV-2 } \\
\text { RT-PCR }\end{array}$ & - & Positive & - \\
\hline $\begin{array}{l}\text { Tracheal } \\
\text { secretion culture }\end{array}$ & & & $\begin{array}{l}\text { Klebsiella pneumoniae, Enterobacter } \\
\text { cloacae, Enterococcus faecalis }\end{array}$ \\
\hline
\end{tabular}

\section{TABLE 1: Ancillary tests during patient hospitalization.}

SARS COV-2 RT-PCR: Severe acquired respiratory syndrome coronavirus 2 reverse-transcriptase polymerase chain reaction

Our initial diagnosis was complicated rhinosinusitis of probable fungal origin, with the following associated diagnoses: severe diabetic ketoacidosis, diabetes mellitus, severe metabolic acidosis, and highly likely atypical pneumonia due to SARS COV-2. Due to severity of infection, we started imipenem/linezolid and 


\section{Cureus}

amphotericin B as empirical treatment.

Direct exam was repeated due to suspicion of a false negative, confirming diagnosis in the next sample, with further culture in Sabouraud media isolating Lichteimia (Absidia) spp (Figure 3). COVID-19 was confirmed with reverse transcriptase-polymerase chain reaction (RT-PCR) of bronchioalveolar fluid (Logix Smart ${ }^{\mathrm{TM}}$, CoDiagnostics, Inc., Salt Lake City, UT, USA).

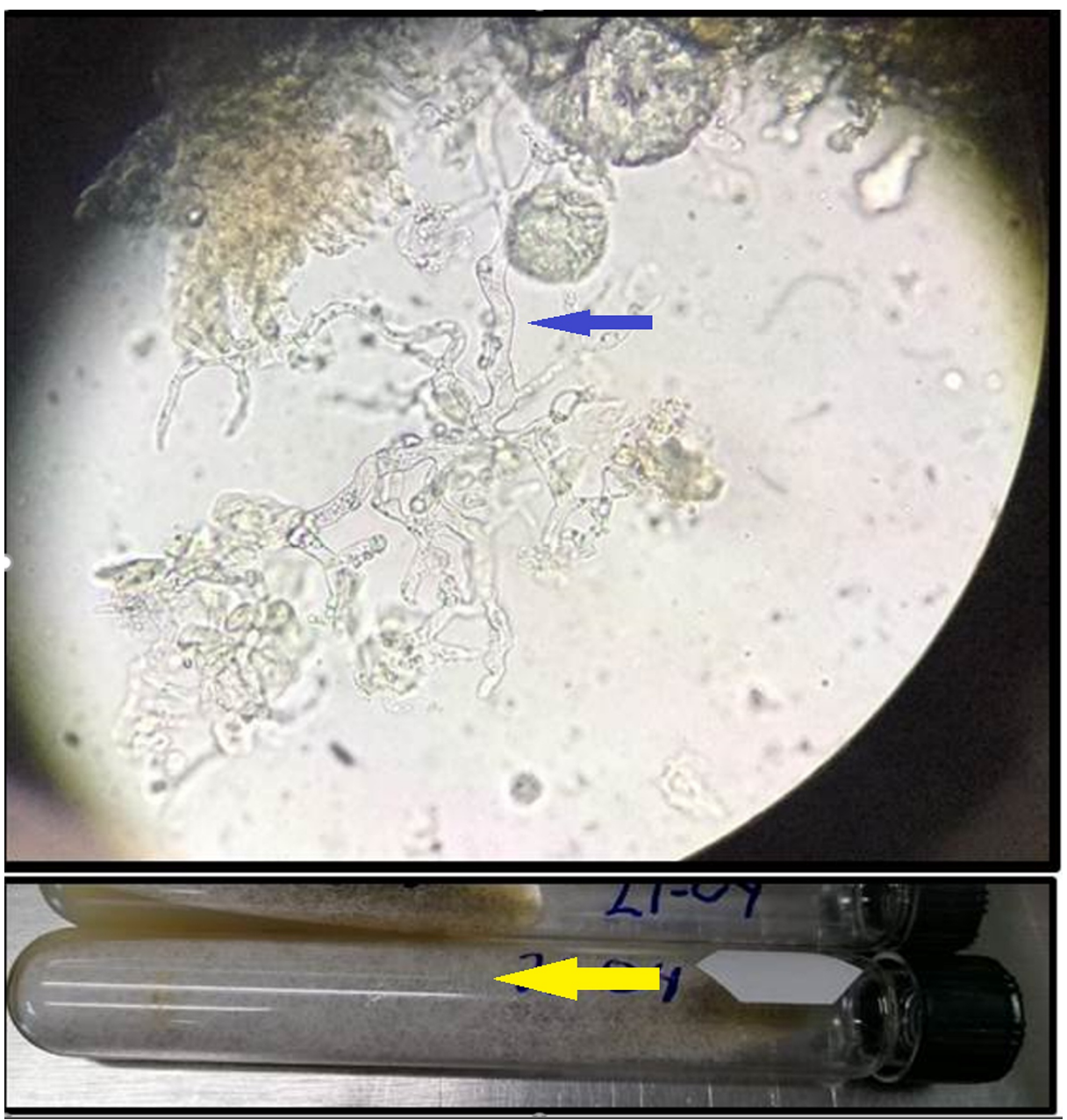

FIGURE 3: Upper image showcasing direct exam with nonseptate, thick hyphae (blue arrow), lower image showcasing philamentous floccose white colonies (yellow arrow).

Even with the established management of the severe diabetic ketoacidosis and mechanical ventilation, the patient had an unfavorable evolution due to refractory metabolic acidosis combined with the pulmonary insult and aggregated acute kidney injury due to disseminated intravascular coagulopathy, which precluded further surgical management, dying of multi-organic failure due to unresponsive septic shock (Figure 4). 


\section{Cureus}

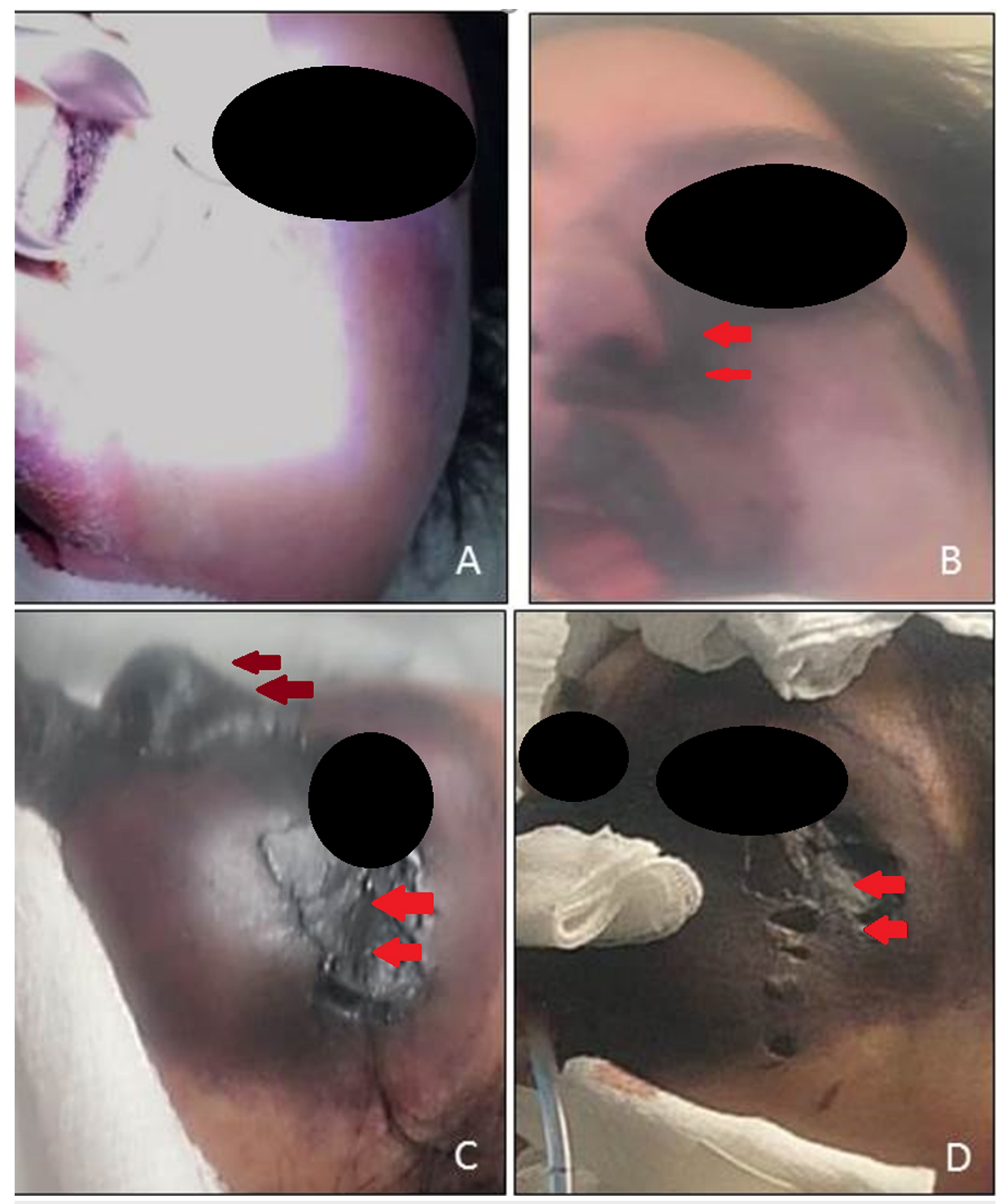

FIGURE 4: Clinical pictures demonstrating the rapid fatal evolution. (A) Admission, (B) first day, (C) second day, (D) third day. Lower lid erythema with progression to a eschar with progressive expansion (red arrows), with further extension to the nasal soft tissues (dark red arrows).

Permission was granted by the patient family to reproduce the clinical photographs.

\section{Discussion}

Mucormycosis is an angioinvasive infection. It is categorized in rhinocerebral, cutaneous, disseminated, gastrointestinal, or pulmonary [6]. In a meta-analysis of 600 series with 851 cases, diabetes mellitus is being reported as the most common underlying condition and an independent factor of rhino-orbital-cerebral mucormycosis, being Rhizopus spp the most common in this group, with an overall mortality of $46 \%$ [7]. Despite these findings, there has been a global increase in cases associated with hematologic neoplasms and organ transplant recipients [8].

In Mexico, diabetes mellitus is also the most common underlying condition with $72 \%$ of the cases reported, of which $75 \%$ had rhinosinusitis, with an overall mortality of $51 \%$ [9].

Baker, an American pathologist retook and coined the term Mucormycosis in 1957 for aggressive infection by Rhizopus [10].

The pathogenic mechanisms implicated in the fungal aggressiveness are the decrease of phagocytic 
function, the more available iron due to displacement of protons by transferrin in diabetic ketoacidosis and the fungal heme oxygenase which facilitates iron uptake for its metabolism [11].

Diagnosis requires rapidness and high index of suspicion due to fulminant progression; the following red flags have been proposed in diabetic patients: cranial nerve palsy, diplopia, mid-facial pain, proptosis, periorbital edema, apex orbital syndrome, and palatine ulcer [6].

According to international guidelines, management must be in a tertiary care center to provide multidisciplinary approach. It is recommended to perform imaging and complimentary endoscopy. If orbit or brain extension, MRI is acquired. Finally, CT imaging should be repeated in unstable patients. Direct exam and histopathology confirm diagnosis. Treatment consists of aggressive surgical debridement, repeating as necessary with adjuvant liposomal amphotericin B (10 mg/kg) [8].

In actual literature there has been reported three rhino-orbitary cases associated with COVID-19 [12-14]. We consider it important to identify the association given the complications and modifications of thrombotic, pulmonary, and metabolic markers both entities share. In our opinion, the immune mechanisms seem to be different due to the fact mycotic dissemination is dependent mostly on modification of phagocytic function; further studies should be performed to determine if this group of patients have further immune dysregulation.

\section{Conclusions}

The COVID-19 pandemic precludes access to pathologies not related with this entity. Due to the high index of suspicion required, late diagnosis in association with an acute respiratory distress syndrome predisposes to a catastrophic scenario. We consider important to report this case to warn of the possibility of COVID-19 as a trigger of diabetic ketoacidosis which could predispose an invasive fungal infection or another high-risk disease. Lastly, we emphasize the hardship of therapeutic decisions in this group of patients with severe coinfections.

In our opinion, the severe immunosuppressive state secondary to diabetic ketoacidosis without previous treatment made the patient susceptible to both severe COVID-19 and mucormycosis.

\section{Additional Information \\ Disclosures}

Human subjects: Consent was obtained by all participants in this study. Conflicts of interest: In compliance with the ICMJE uniform disclosure form, all authors declare the following: Payment/services info: All authors have declared that no financial support was received from any organization for the submitted work. Financial relationships: All authors have declared that they have no financial relationships at present or within the previous three years with any organizations that might have an interest in the submitted work. Other relationships: All authors have declared that there are no other relationships or activities that could appear to have influenced the submitted work.

\section{References}

1. Martínez-López R: Ecología de los hongos patógenos para el hombre . Rev Mex Mic. 2005, 21:85-92.

2. Martínez-López R: Estudio de hongos atmosféricos en un medio hospitalario . Gac Med Mex. 1984, 120:387396.

3. Lansbury L, Lim B, Baskaran V, Lim WS: Co-infections in people with COVID-19: a systematic review and meta-analysis. SSRN Electron J. 2020, 10.2139/ssrn.3594598

4. Zhu X, Ge Y, Wu T, et al.: Co-infection with respiratory pathogens among COVID-2019 cases . Virus Res. 2020, 285:198005. 10.1016/j.virusres.2020.198005

5. Song G, Liang G, Liu W: Fungal co-infections associated with global COVID-19 pandemic: a clinical and diagnostic perspective from China. Mycopathologia. 2020, 185:599-606.

6. Suganya R, Malathi N, Karthikeyan V, Janagaraj VD: Mucormycosis: a brief review . J Pure Appl Microbiol. 2019, 13:161-165. 10.22207/JPAM.13.1.16

7. Jeong W, Keighley C, Wolfe R, et al.: The epidemiology and clinical manifestations of mucormycosis: a systematic review and meta-analysis of case reports. Clin Microbiol Infect. 2019, 25:26-34. 10.1016/j.cmi.2018.07.011

8. Cornely OA, Alastruey-Izquierdo A, Arenz D, Chen SCA, Dannaoui E, Hochhegger B; Mucormycosis ECMM MSG Global Guideline Writing Group: Global guideline for the diagnosis and management of mucormycosis: an initiative of the European Confederation of Medical Mycology in cooperation with the Mycoses Study Group Education and Research Consortium. Lancet Infect Dis. 2019, 19:405-421. 10.1016/S14733099(19)30312-3

9. Corzo-León DE, Chora-Hernández LD, Rodríguez-Zulueta AP, Walsh TJ: Diabetes mellitus as the major risk factor for mucormycosis in Mexico: epidemiology, diagnosis, and outcomes of reported cases. Med Mycol. 2018, 56:29-43. 10.1093/mmy/myx017

10. Baker RD: Mucormycosis-a new disease?. J Am Med Assoc. 1957, 163:805-808. 10.1001/jama.1957.02970450007003

11. Ibrahim AS, Spellberg B, Walsh TJ, Kontoyiannis DP: Pathogenesis of mucormycosis. Clin Infect Dis. 2012, 


\section{Cureus}

54:1-7. 10.1093/cid/cir865

12. Mekonnen ZK, Ashraf DC, Jankowski T, et al.: Acute invasive rhino-orbital mucormycosis in a patient with COVID-19-associated acute respiratory distress syndrome. Ophthalmic Plast Reconstr Surg. 2020, In press. 10.1097/IOP.0000000000001889

13. Mehta S, Pandey A: Rhino-orbital mucormycosis associated with COVID 19. Cureus. 2020, 12:10-14. 10.7759/cureus.10726

14. Werthman-Ehrenreich A: Mucormycosis with orbital compartment syndrome in a patient with COVID-19 . Am J Emerg Med. 2020, In press. 10.1016/j.ajem.2020.09.032 